\title{
Effect of alcohol concentration and electrode composition on the ethanol electrochemical oxidation
}

\author{
K. Bergamaski', J. F. Gomes ${ }^{1}$, B. E; Goi ${ }^{1}$, F. C. Nart ${ }^{1}$ \\ ${ }^{1}$ Instituto de Química de São Carlos - USP - CEP 13560-970- São Carlos - SP - Brasil
}

\begin{abstract}
The electrochemical oxidation on platinum and platinum rhodium bimetallic electrodes was studied by Differential Electrochemical Mass Spectrometry for several ethanol concentrations in solution. It is found that increasing the ethanol concentration the production of the partially oxidized products (acetaldehyde) increases as the concentration increases. On the other hand, addition of $25 \%$ at. of rhodium increases the full oxidation to $\mathrm{CO}_{2}$. Another interesting result observed is a correlation between the intensity of the dehydrogenations peak at $0.3 \mathrm{~V}$ vs. RHE and the $\mathrm{CO}_{2}$ yield for the different ethanol concentration studied.
\end{abstract}

Keywords: electrocatalysis; platinum-rhodium; DEMS; reaction pathways.

\section{Introduction}

The research on the direct methanol fuel cell attracted the attention of many groups around the world in the last two decades. Methanol has been considered as a good fuel for fuel cell applications because it is a liquid at room temperature, which makes handling much easier than hydrogen. Another alternative as a fuel is ethanol. In contrast with methanol, the electrochemical oxidation of ethanol to carbon dioxide is not so easy. On the other hand, ethanol is less toxic than methanol and can be easily obtained from fermentation processes. In addition, the permeability of ethanol through nafion membranes is much lower than methanol [1], preventing the cross over of the fuel that causes depolarization of the cathode. The drawback of ethanol is the kinetic of ethanol electrochemical oxidation that leads preferentially to partially oxidized products [2]. The main products observed during ethanol electrochemical oxidation on platinum electrodes are acetaldehyde, acetic acid and carbon dioxide, with predominance for acetic acid and acetaldehyde. It has been reported that some bimetallic electrodes can improve considerably the fully oxidation to $\mathrm{CO}_{2}[3,4]$. In fact, in a recent publication it is shown that platinum-rhodium alloy electrodes can improve the fully oxidation of ethanol to $\mathrm{CO}_{2}$ [4]. The better electrode composition reported was an electrode containing 25 atomic percentage of rhodium in the electrode composition. On the other hand, platinumruthenium bimetallic electrodes promote a decrease in the onset potential for ethanol oxidation, but do not change the $\mathrm{CO}_{2} / \mathrm{CH}_{3} \mathrm{CHO}$ ratio [5].

The contact of ethanol with the electrode surface yields some very strong adsorbed species. The main strongly bonded ethanol fragment is $\mathrm{CO}$, but other hydrogenated adsorbates are found

This paper is dedicated to Prof. Ernesto Rafael Gonzalez for his outstanding contributions to the Electrochemistry in Brazil. 
by in situ infrared spectroscopy experiments [6]. In this way, electrodes that oxidize $\mathrm{CO}$ at lower potential are very important to improve the electrocatalytic oxidation of ethanol. Improvement of $\mathrm{CO}$ to $\mathrm{CO}_{2}$ oxidation has been reported for PtRu bimetallic electrodes [5], probably following a bifunctional mechanism as that proposed for methanol oxidation [7]. However an effect on the CO bonding energy was proposed for this kind of material, based on in situ measurement of the adsorbed $\mathrm{CO}$ vibration [8].

Another characteristic of alcohol electrochemical oxidation reaction is the effect of alcohol concentration on the distribution of the oxidation products. It has been reported that higher concentrations favor the less oxidized products [2]. However a more systematic study on the effect of the concentration is still lacking. It is the purpose of this study to report data on the effect of electrode composition and of ethanol concentration on the selectivity of the electrochemical oxidation of ethanol. DEMS and cyclic voltammetry are used as experimental techniques in order to access both the reactivity and the distribution of the oxidation products, namely carbon dioxide and acetaldehyde.

\section{Experimental}

The differential electrochemical mass spectrometry (DEMS) was used for on line detection of volatile and gaseous products formed during the electrochemical oxidation $[9,10]$. The electrochemical cell used was similar that used by Ianniello and Schmidt [11]. A reversible hydrogen electrode (RHE) in the electrolyte solution and a platinized Pt foil were used as reference and counter electrode, respectively. The working electrodes were prepared by potentiostatic deposition on sputtered Au substrate electrodes. The atomic bulk composition of the electrodeposited electrode was checked by energy dispersive analysis of X-rays (EDAX).

Electrochemical cyclic voltammograms $(\mathrm{CVs})$ and mass spectrometry cyclic voltammograms (MSCVs) were obtained with a potentiostat model RDE4 of Pine Instrument Company and MKS Instruments for quadrupole mass spectrometer.

CVs and MSCVs were obtained in 0.1 mol L-1 $\mathrm{HClO}_{4}$ base electrolyte in several ethanol concentrations using $\mathrm{Pt}$ and $\mathrm{Pt}_{75} \mathrm{Rh}_{25}$ electrodes in order to compare their electrocatalytic activities. The potential sweeps were performed at $0.01 \mathrm{~V} . \mathrm{s}^{-}$ ${ }^{1}$ in the range of $0.05-1.4 \mathrm{~V}$ for pure $\mathrm{Pt}$ and 0.05 - $1.0 \mathrm{~V}$ for $\mathrm{Pt}_{75} \mathrm{Rh}_{25}$ bimetallic electrode. The utilization of isotope labeled ethanol permits us the products identification. The formation of carbon dioxide $\left(\mathrm{CO}_{2}\right)$ and acetaldehyde $\left(\mathrm{CD}_{3} \mathrm{CHO}\right)$ were distinguished by ion currents at $\mathrm{m} / \mathrm{z}=44$ and $\mathrm{m} / \mathrm{z}=47$, respectively.

Before each experiment, the electrode was cycled in Ar saturated perchloric acid solution until a reproducible voltammogram was obtained. So, the ethanol addition in the electrochemical cell was realized with polarized electrode at $0.05 \mathrm{~V}$. After that, the electrooxidation was carried out in the positive-going potential scan.

The solutions were prepared with Millipore-MilliQä water and analytical grade chemicals; $\mathrm{HClO}_{4}$ (Merck), $\mathrm{CD}_{3} \mathrm{CH}_{2} \mathrm{OH}$ (99\% D, Aldrich), $\mathrm{H}_{2} \mathrm{PtCl}_{6} \cdot 6 \mathrm{H}_{2} \mathrm{O}$ (Aldrich), $\mathrm{RhCl}_{3} \cdot 3 \mathrm{H}_{2} \mathrm{O}$ (Aldrich).

\section{Results}

The results of the electrochemical current and the mass signal for $\mathrm{CO}_{2}(\mathrm{~m} / \mathrm{z}=44)$ and $\mathrm{CD}_{3} \mathrm{CHO}(\mathrm{m} / \mathrm{z}=47)$ during ethanol oxidation on electrodeposited Pt are shown in Fig. 1 for two different ethanol concentrations. The other curves were similar, differing only in the intensity of the signals. Note that these results do not present an absolute measure of selectivity, since the mass intensity signal $\mathrm{m} / \mathrm{z}=47$ do not correspond to the total $\mathrm{CD}_{3} \mathrm{CHO}$ produced. A more complete survey of data are given in Table 1 for the platinum electrode, where the mass intensity for $\mathrm{CO}_{2}$ and $\mathrm{CD}_{3} \mathrm{CHO}$ and the mass intensity ratios $\left(\mathrm{R}_{\mathrm{int}}\right)$ calculated from the results of Fig. 1 are shown. The data reported in Table 1 were obtained by subtracting the value at $0.7 \mathrm{~V}$ from the background signals for the current and mass signals in the anodic scans. 


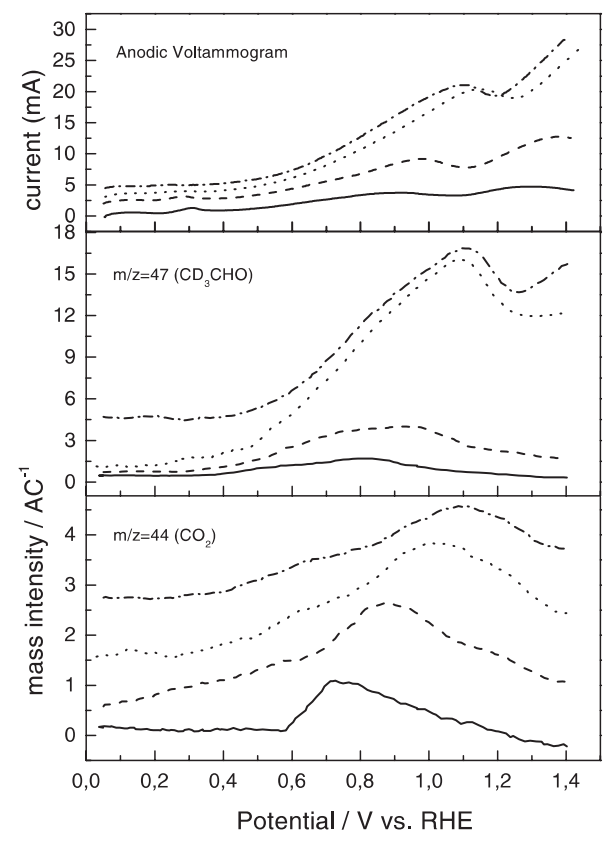

Figure 1. Anodic voltammograms and mass signal $(\mathrm{m} / \mathrm{z}=47$ and $\mathrm{m} / \mathrm{z}=44)$ for the oxidation of ethanol on platinum at different ethanol concentrations: (-) $0.01 \mathrm{~mol} \mathrm{~L}^{-1}$; (----) $0.1 \mathrm{~mol} \mathrm{~L}^{-1}$; (L) $0.5 \mathrm{~mol} \mathrm{~L}^{-1}$; ('-*-) $1.0 \mathrm{~mol} \mathrm{~L}^{-1}$.

Table 1. Mass intensities of $\mathrm{CO}_{2}$ and acetaldehyde and $\mathrm{m}=\mathrm{z}=44 / \mathrm{m} / \mathrm{z}=47$ ratios at $0.70 \mathrm{~V}$ as a function of the ethanol concentration for pure Pt electrode.

\begin{tabular}{ccccc}
\hline Method & $\mathbf{d}_{\mathbf{D R X}} / \mathbf{n m}$ & $\mathbf{S} / \mathbf{~ m}^{\mathbf{2}} \mathbf{g}^{-\mathbf{1}} \mathbf{P t}$ & $\mathbf{a} / \mathbf{n m}$ & $\mathbf{d}_{\text {MET }} / \mathbf{n m}$ \\
\hline MAF & 4,5 & 62 & $0,39075 \pm 0,00193$ & $3,2-5,4$ \\
MW & 5,4 & 52 & $0,39075 \pm 0,00188$ & $2,7-5,5$ \\
MB & 4,4 & 64 & $0,39102 \pm 0,00079$ & $3,0-3,9$ \\
MS & 9,3 & 30 & $0,39152 \pm 0,00274$ & $3,1-5,3$ \\
E-TEK & 2,8 & 100 & $0,39041 \pm 0,00285$ & $1,6-3,0$ \\
\hline
\end{tabular}

At low concentrations (Fig. 2), a peak near $0.30 \mathrm{~V}$ can be seen in the cyclic voltammograms. This well defined peak is assigned to ethanol dehydrogenation on the surface [8]. This peak is observed only during the first potential scan, when ethanol is added to the cell with the electrode polarized at $0.05 \mathrm{~V}$, since the electrode surface is protected by ethanol adsorption by the presence of adsorbed hydrogen on platinum. In the subsequent scans the electrode surface becomes contaminated and the dehydrogenation peak is no longer observed. For concentrations higher than $0.1 \mathrm{~mol} \mathrm{~L}^{-1}$ this peak is very weak. This peak decreases the intensity as the ethanol concentration is increased (see Fig. 1 for comparison of the intensties). 


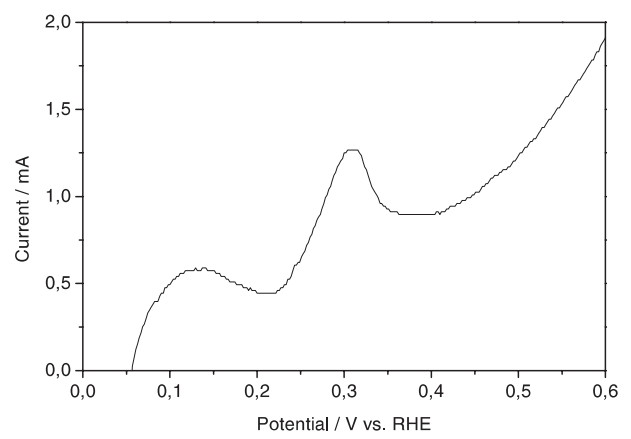

Figure 2. Anodic scan of the ethanol oxidation on platinum electrode for the ethanol admitted to the cell with the electrode at $0.05 \mathrm{~V}$ to avoid ethanol decomposition. Ethanol concentration $0.01 \mathrm{~mol} \mathrm{~L}^{-1}$.

From the results of Table 1, it is clear that $\mathrm{CD}_{3} \mathrm{CHO}$ is the main product for all the ethanol concentrations studied, while $\mathrm{CO}_{2}$ is a minor product (it is important to stress that the $\mathrm{m} / \mathrm{z}=29$ is only part of the $\mathrm{CD}_{3} \mathrm{CHO}$ produced). Both the electrochemical current density and the mass signal for $\mathrm{CO}_{2}$ and $\mathrm{CD}_{3} \mathrm{CHO}$ increase with the alcohol concentration, as expected. Although production of $\mathrm{CD}_{3} \mathrm{CHO}$ is the main route, the results shown in Table 1 clearly indicate that there is a change in the relation between the $\mathrm{CO}_{2}$ and $\mathrm{CD}_{3} \mathrm{CHO}$ yield with the alcohol concentration. The decrease in the $\mathrm{CO}_{2} / \mathrm{CD}_{3} \mathrm{CHO}$ ratio is due to an increase of
$\mathrm{CD}_{3} \mathrm{CHO}$ mass signal for higher ethanol concentrations.

The results for $\mathrm{Pt}_{75} \mathrm{Rh}_{25}$ alloy electrode are reported in Fig. 3 for two different concentrations and the current density and mass signals for $\mathrm{CO}_{2}$ and $\mathrm{CD}_{3} \mathrm{CHO}$ obtained at $0.7 \mathrm{~V}$ are given in Table 2. Analyzing more in detail the curves of Fig. 3, it is clear that the onset potential for $\mathrm{CO}_{2}$ and $\mathrm{CD}_{3} \mathrm{CHO}$ production is shifted to less positive potentials, compared with the same curves of Fig. 1. Furthermore, the onset seems to be concentration dependent in the case of the bimetallic $\mathrm{Pt}_{75} \mathrm{Rh}_{25}$ electrode.

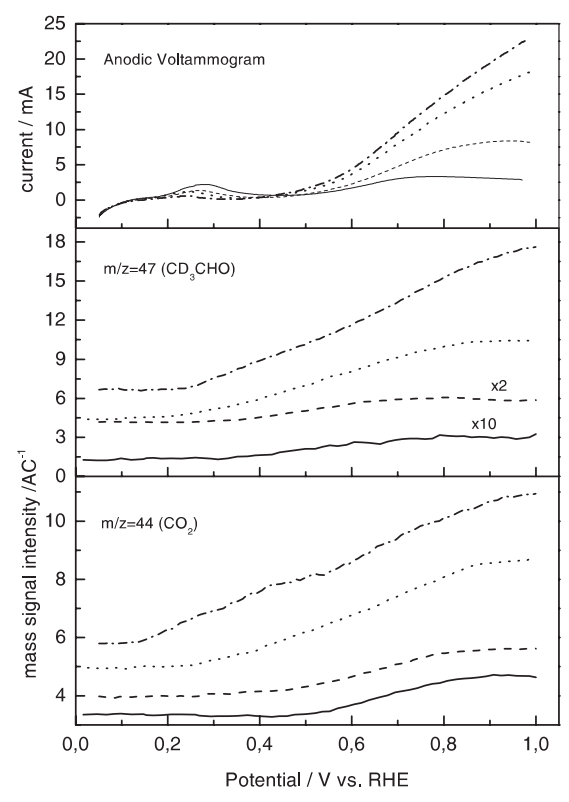

Figure 3. Anodic voltammograms and mass signal $(\mathrm{m} / \mathrm{z}=47$ and $\mathrm{m} / \mathrm{z}=44)$ for the oxidation of ethanol on $\mathrm{Pt}_{75} \mathrm{Rh}_{25}$ bimetallic electrode at different ethanol concentrations: (一) $0.01 \mathrm{~mol} \mathrm{~L}^{-1}$; (----) $0.1 \mathrm{~mol} \mathrm{~L}^{-1}$; (L) $0.5 \mathrm{~mol} \mathrm{~L}^{-1}$; (----) $1.0 \mathrm{~mol} \mathrm{~L}^{-1}$. 
For lower ethanol concentration the dehydrogenation reaction is shown in Fig. 4. Again, compared with the same result for the pure platinum electrode (Fig. 2), the dehydrogenation peak is more intense and displaced to less positive potentials. The dehydrogenation peak decreases with the increase in ethanol concentration, as in the case of pure platinum.

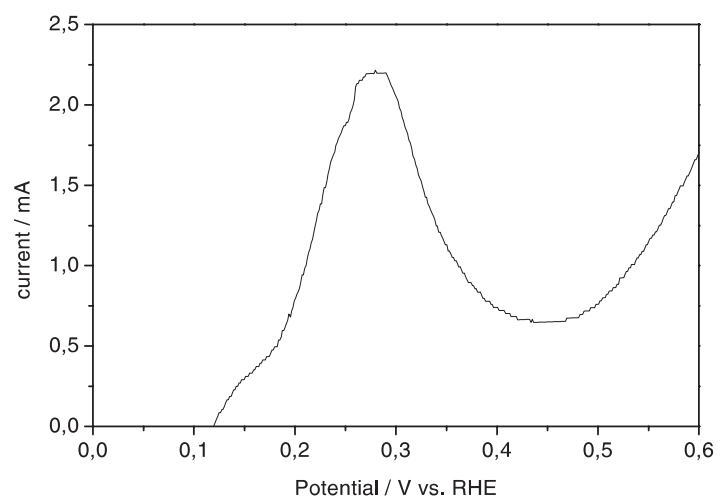

Figure 4. Anodic scan of the ethanol oxidation on $\mathrm{Pt}_{75} \mathrm{Rh}_{25}$ bimetallic electrode for the ethanol admitted to the cell with the electrode at $0.05 \mathrm{~V}$ to avoid ethanol decomposition. Ethanol concentration $0.01 \mathrm{~mol} \mathrm{~L}^{-1}$.

The normalized mass signal for $\mathrm{CO}_{2}$ is clearly higher for the alloy than for the platinum electrode for all concentrations studied (see Table 2), showing that the $\mathrm{Pt}_{75} \mathrm{Rh}_{25}$ electrode increases the production of $\mathrm{CO}_{2}$ compared to the pure platinum electrode. However the mass signal for the $\mathrm{CD}_{3} \mathrm{CHO}$ are lower for the alloy electrode for ethanol concentrations lower than $0.5 \mathrm{~mol} \mathrm{~L}^{-1}$ and almost the same for ethanol $1 \mathrm{~mol} \mathrm{~L}^{-1}$. Consequently the ration $\mathrm{CO}_{2} / \mathrm{CD}_{3} \mathrm{CHO}$ is higher for the alloy electrode by a factor of ca. 3.0 times that obtained for the pure platinum electrode, except of the 0.01 mol L ${ }^{-1}$ ethanol concentration where this difference is of ca. 12 times, confirming the higher $\mathrm{CO}_{2}$ selectivity for the bimetallic $\mathrm{Pt}_{75} \mathrm{Rh}_{25}$ electrode. In both cases the selectivity to $\mathrm{CO}_{2}$ decreases with the increase of ethanol concentration.

\section{Discussion}

The marked effect of rhodium addition on the selectivity to ethanol oxidation to $\mathrm{CO}_{2}$ is related the higher dehydrogenation efficiency, as shown in the Figs. 2 and 4. To understand this effect we have to consider the reaction pathways of these two products. The complete ethanol oxidation to $\mathrm{CO}_{2}$ involves the full dehydrogenation, $\mathrm{C}-\mathrm{C}$ bond dissociation with consequent formation of adsorbed carbon monoxide and finally its oxidation to $\mathrm{CO}_{2}$ whereas the route of the $\mathrm{CD}_{3} \mathrm{CHO}$ involves only the loss of two protons. This increased ability to remove protons from the ethanol probably facilitates the formation of adsorbed fragments with only one carbon and consequently the oxidation to $\mathrm{CO}_{2}$. The reasons to this higher efficiency to remove protons may be related with the interaction of the ethanol molecule with the metallic surface. It is already known from UHV experiments that ethanol adsorbs on rhodium forming a cyclic adsorbate, thus leading to a very stressed $\mathrm{C}-\mathrm{C}$ bond [12]. Although there are no data for platinum-rhodium bimetallic surfaces it is likely that a similar kind of adsorbed intermediate must be present also on this kind of surface as well. Thus the facility in removing protons seems to be the main cause for the increased selectivity of ethanol oxidation to $\mathrm{CO}_{2}$. This can be confirmed by the fact that the decrease in the ration $\mathrm{CO}_{2} / \mathrm{CD}_{3} \mathrm{CHO}$ with the increase of ethanol concentration follows a decrease in the intensity of the dehydrogenation peak.

A point to be discussed is why the increase in ethanol concentration inhibits the dehydrogenation peak at ca $0.3 \mathrm{~V}$ with a consequent higher yield for acetaldehyde. As discussed above the higher production of $\mathrm{CO}_{2}$ is directly related to the higher ethanol dehydrogenation at potentials at ca. $0.3 \mathrm{~V}$. Therefore, it is reasonable to conclude that $\mathrm{CO}_{2}$ is originated from the oxidation of the dissociated species from ethanol on the surface. In this way, it could be proposed that $\mathrm{CO}_{2}$ production would be limited by the coverage degree for this species in the electrode surface. For the high ethanol concentration, the electrode surface becomes quickly recovered by a high amount of undissociated ethanol molecules, competing with the stronger adsorption for the ethanol dehydrogenation on surface. At lower concentrations there is less competition for sites at the surface and the more strongly adsorbate takes place. The reason for the preference for the weakly adsorbed ethanol with not extensive dehydrogenation may rely on kinetic reasons. The weak adsorption with acetaldehyde formation must be faster than the strong adsorption with loss of practically all protons to form the fully 
undissociated adsorbates on the surface. In lower concentrations there are not so many species that reach the surface and the slow reaction of the strongly adsorbate can compete with the weak one. Finally it is important to consider the low onset potential of the $\mathrm{CO}_{2}$ and acetaldehyde in the case of the $\mathrm{Pt}_{75} \mathrm{Rh}_{25}$ bimetallic electrode. In contrast with PtRu bimetallic electrodes, both $\mathrm{CO}_{2}$ and acetaldehyde onset potentials are shifted to less positive potential, which indicates that the catalytic mechanism of the PtRh bimetallic electrode is not only the well discussed bifunctional mechanism, as proposed for PtRu bimetallic electrodes, but a more complex mechanism, involving the electronic structure of the surface, that facilitates the interaction of the ethanol molecule with the surface. Thus the reason for observed differences between PtRh and PtRu bimetallic electrodes is due to the different action of second element at the surface.

\section{Conclusions}

In summary, the results show that the $\mathrm{Pt}_{75} \mathrm{Rh}_{25}$ bimetallic electrode is more catalytic than pure platinum for the fully oxidation of ethanol to $\mathrm{CO}_{2}$ for all the ethanol concentrations studied. It has been shown that there is a good correlation between the extension of the dehydrogenation reaction at the beginning of the reaction and the production of $\mathrm{CO}_{2}$, revealing that a more extensive dehydrogenation destabilizes the ethanol molecule on the surface, facilitating the $\mathrm{C}-\mathrm{C}$ bond dissociation.

On the electrode surface there is a strong competition between a weakly bonded and a strongly bonded adsorbate and increasing the ethanol concentration the kinetic to pathway via the weakly bonded ethanol prevails over that for the pathway via the strongly bonded adsorbate. The immediate consequence is an increase in the production of acetaldehyde over $\mathrm{CO}_{2}$.

\section{Acknowledgements}

The authors are grateful to FAPESP, CNPQ and CAPES for financial support to this work.

K. Bergamaski, J. F. Gomes, B. E; Goi, F. C. Nart. Efeito da concentração do álcool e da composição do eletrodo na oxidação eletroquímica do etanol.

Resumo: A oxidação eletroquímica de etanol foi estudada sobre eletrodos de platina e de platina-ródio, usando Espectrometria Eletroquímica Diferencial de Massa, para várias concentrações de etanol em solução. Os resultados indicaram que o aumento na concentração de etanol aumentou a formação do produto parcialmente oxidado (acetaldeído). Por outro lado, a adição de $25 \%$ at. de ródio aumentou a oxidação completa a $\mathrm{CO}_{2}$. Para as diferentes concentrações de etanol estudadas, foi observada também uma correlação entre a intensidade do pico de desidrogenação a 0,3 V vs. ERH e o rendimento de $\mathrm{CO}_{2}$.

Palavras-chave: eletrocatálise; platina-ródio; DEMS; caminhos de reação.

\section{References}

[1] A. Heinzel, V. M. Barragan. J. Power Sources, 84 (1999) 70 [2] T. Iwasita, B. Rasch, E. Cattaneo, W. Vielstich. Electrochim. Acta, 34 (1989) 1073

[3] J. P. I. Souza, J. F. B. Rabello, I. R. Moraes, F. C. Nart. J. Electroanal. Chem. 420 (1997) 17

[4] J. P. I. Souza, S. L. Queiroz, K. Bergamaski, E. R. Gonzalez, F. C. Nart. J. Phys. Chem. 106 (2002) 9825

[5] N. Fukiwara, K. A. Friedrich, U. Stimming, J. Electroanal. Chem. 472 (1999) 120

[6] T. Iwasita, E. Pastor. Electrochim. Acta 39 (1994) 531
[7] M. Watanabe, M. Uchida, S. Motoo. J. Electroanal. Chem. 229 (1987) 395

[8] T. Iwasita, F. C. Nart, W. Vielstich. Ber. Bunsenges. Phys. Chem. 94 (1990) 1030

[9] O. Wolter, J. Heitbaum. Ber. Bunsenges. Phys. Chem. 88 (1984) 2.

[10] J. P. I. Souza, S. L. Queiroz, F. C. Nart. Quim. Nova 23 (2000) 384

[11] R. Ianniello, V. M. Schidt. Ber. Bunsenges. Phys. Chem. 99 (1995) 83.

[12] C. J. Houtman, M. A. Barteau. J. Catal. 130 (1991) 528 